\title{
Mechanisms of laccase-mediator treatments improving the enzymatic hydrolysis of pre-treated spruce
}

\author{
Ulla Moilanen ${ }^{1 *}$, Miriam Kellock ${ }^{1,2}$, Anikó Várnai ${ }^{1,3}$, Martina Andberg ${ }^{2}$ and Liisa Viikari ${ }^{1}$
}

\begin{abstract}
Background: The recalcitrance of softwood to enzymatic hydrolysis is one of the major bottlenecks hindering its profitable use as a raw material for platform sugars. In softwood, the guaiacyl-type lignin is especially problematic, since it is known to bind hydrolytic enzymes non-specifically, rendering them inactive towards cellulose. One approach to improve hydrolysis yields is the modification of lignin and of cellulose structures by laccase-mediator treatments (LMTs).
\end{abstract}

Results: LMTs were studied to improve the hydrolysis of steam pre-treated spruce (SPS). Three mediators with three distinct reaction mechanisms (ABTS, HBT, and TEMPO) and one natural mediator (AS, that is, acetosyringone) were tested. Of the studied LMTs, laccase-ABTS treatment improved the degree of hydrolysis by 54\%, while acetosyringone and TEMPO increased the hydrolysis yield by $49 \%$ and 36\%, respectively. On the other hand, laccase-HBT treatment improved the degree of hydrolysis only by $22 \%$, which was in the same order of magnitude as the increase induced by laccase treatment without added mediators (19\%). The improvements were due to lignin modification that led to reduced adsorption of endoglucanase Cel5A and cellobiohydrolase Cel7A on lignin. TEMPO was the only mediator that modified cellulose structure by oxidizing hydroxyls at the C6 position to carbonyls and partially further to carboxyls. Oxidation of the reducing end C1 carbonyls was also observed. In contrast to lignin modification, oxidation of cellulose impaired enzymatic hydrolysis.

Conclusions: LMTs, in general, improved the enzymatic hydrolysis of SPS. The mechanism of the improvement was shown to be based on reduced adsorption of the main cellulases on SPS lignin rather than cellulose oxidation. In fact, at higher mediator concentrations the advantage of lignin modification in enzymatic saccharification was overcome by the negative effect of cellulose oxidation. For future applications, it would be beneficial to be able to understand and modify the binding properties of lignin in order to decrease unspecific enzyme binding and thus to increase the mobility, action, and recyclability of the hydrolytic enzymes.

Keywords: Enzymatic hydrolysis, Laccase, Mediator, Lignin, Cellulose oxidation, Spruce

\section{Background}

To meet the current targets for the production of liquid fuels based on renewable sources, lignocellulosic feedstocks will have to be utilized in increasing amounts. Lignocellulosic biomass is, however, a challenging raw material because of its recalcitrant structure. It is composed mainly of structural polysaccharides that are more difficult to degrade into fermentable sugars than storage

\footnotetext{
* Correspondence: ulla.moilanen@helsinki.fi

'Department of Food and Environmental Sciences, University of Helsinki, PO Box 27, Helsinki 00014, Finland

Full list of author information is available at the end of the article
}

polysaccharides such as starch. The crystalline structure of cellulose makes it highly resistant to enzymatic hydrolysis. In addition, hemicelluloses and lignin form a complex network that shields cellulose from enzymatic attack $[1,2]$. Lignin is especially problematic, since the most common pre-treatment methods, such as steam pre-treatment, solubilize most of the hemicelluloses but leave modified lignin behind in the insoluble matrix [3]. In addition to blocking the cellulose surface from the hydrolytic enzymes, lignin is known to bind enzymes non-specifically [4-8], rendering them inactive towards cellulose, especially at hydrolysis temperatures [9]. 
Softwoods are an abundant source of lignocellulosic biomass in the Northern Hemisphere, and therefore their use as feedstock for liquid fuel production has aroused interest. Softwoods are, however, difficult to degrade with hydrolytic enzymes because of the structure of lignin. Softwood lignin is largely of the guaiacyl (G) type and has been shown to inhibit the enzymatic hydrolysis of cellulose more strongly than hardwood or grass lignin [10].

One way to improve the yields of the enzymatic hydrolysis of softwood would be the use of laccase-mediator treatments (LMTs) to modify the lignin and possibly the cellulose structure. Laccases (benzenediol: oxygen oxidoreductase, EC 1.10.3.2) are multi-copper oxidases able to oxidize various phenolic compounds by one electron transfer with the concomitant reduction of oxygen to water $[11,12]$. Laccases can only oxidize phenols and aromatic or aliphatic amines that have lower redox potential than the laccase $(<0.4-0.8 \mathrm{~V})$ and are small enough to enter the active center of the enzyme [13]. With the aid of low molecular weight substrate molecules as mediators, oxidation by laccases can, however, be expanded to larger molecules unable to fit into the enzymatic pocket or even to non-phenolic compounds that are not actual substrates of laccases $[14,15]$.

Several mechanisms for the oxidation of substrates by mediators have been proposed. ABTS (2,2,--azino-bis(3-ethylbenzothiazoline-6-sulfonic acid)) is thought to oxidize the substrate by an electron transfer (ET) mechanism where one electron is removed from the substrate $[14,16]$. N-OH type mediators such as HBT (1-hydroxybenzotriazole) are likely to act through a radical hydrogen atom transfer (HAT) route, where the mediator is oxidized into a radical that can oxidize a substrate having a higher redox potential than the mediator itself. With the HAT route, a hydrogen atom is transferred from the substrate to the mediator, as opposed to the ET route where only the electron is transferred to the mediator and the $\mathrm{H}^{+}$ion from the substrate is released into the medium $[17,18]$. Oxidation with TEMPO (2,2,6,6-tetramethylpiperidine-1-oxyl) is understood to differ from these two reactions and involve an ionic mechanism. TEMPO is a stable $\mathrm{N}$-oxyl radical that is oxidized to a reactive oxoammonium ion by laccase. The oxoammonium ion is proposed to oxidize the primary hydroxyl via a base attack. The ionic oxidation mechanism is not dependent on the redox potential of the substrate [17,19-21].

Since the discovery of the enhancing effect of mediators, especially in lignin degradation, the use of LMTs has been studied for many applications in lignocellulosics, such as pulp bleaching and refining as well as other fiber modifications (reviewed by Widsten and Kandelbauer [22]). In addition, LMTs have been used in several other application areas; in organic synthesis LMTs can catalyze diverse reactions, and in waste water treatment they can detoxify or remove xenobiotic compounds, such as textile dyes and chlorophenols (reviewed in [23-25]). In recent years, LMT research has focused on finding natural mediators to replace synthetic ones [26]. Natural mediators can be either fungal phenolic metabolites or lignin-derived phenols $[27,28]$. The advantage of natural mediators is that they may be less toxic and that they could be produced at a lower cost than synthetic ones. In addition, some can be available in the lignocellulosic raw material [26].

In this paper, LMTs were studied to improve the hydrolysis of pre-treated spruce. Three mediators with three distinct reaction mechanisms (ABTS, HBT, and TEMPO) and one natural mediator (AS, that is, acetosyringone) were tested. The structures of the mediators are shown in Figure 1. Laccase-mediator systems have generally been targeted to act specifically on the lignin moiety of the lignocellulosic substrates. Thus, their possible impacts on cellulose and therefore on enzymatic cellulose hydrolysis have been insufficiently studied. In this study, the effect of LMT on both cellulose and lignin fractions was investigated.

\section{Results and discussion}

The effect of LMTs on the enzymatic hydrolysis of steam pre-treated spruce

To improve the degree of enzymatic hydrolysis of steam pre-treated spruce (SPS), the substrate was treated with Trametes hirsuta laccase alone or in combination with one of the mediators ABTS, HBT, TEMPO, or AS prior to enzymatic hydrolysis. The LMTs were studied at various mediator concentrations $(0.5,1,3$, and $10 \mathrm{mM})$. Laccase treatment alone increased hydrolysis by $19 \%$ compared with the reference, which was not treated by laccase (Figure 2). This increase is in the same order of magnitude as reported in previous studies, where laccase treatment without added mediators improved the enzymatic hydrolysis of SPS by 12 to $13 \%[29,30]$.

In this study, all LMTs improved the enzymatic hydrolysis of SPS. Notably, of the tested laccase and mediator combinations, the laccase and ABTS treatment gave the most marked improvement in the degree of hydrolysis. A $54 \%$ increase in conversion was observed when laccase and $10 \mathrm{mM}$ of ABTS were used. Similarly, AS was found to be an effective laccase mediator in higher doses; when loaded at $10 \mathrm{mM}$ concentration, it provided an increase of $49 \%$ compared with the reference. TEMPO also improved enzymatic conversion of SPS to sugars; $3 \mathrm{mM}$ TEMPO enhanced the hydrolysis by $36 \%$. When TEMPO was used at $10 \mathrm{mM}$ concentration, however, the hydrolysis yield was impaired since the laccase treatment alone led to higher yields of released sugars. Surprisingly, the use of HBT did not enhance the degree of hydrolysis further.

There are only a few studies where LMTs have been used to improve the enzymatic hydrolysis of lignocellulose- 
<smiles>CCn1/c(=N/N=c2\sc3cc(S(=O)(=O)O)ccc3n2CC)sc2cc(S(=O)(=O)O)ccc21</smiles><smiles>On1nnc2ccccc21</smiles>

HBT<smiles>CC1(C)CCCC(C)(C)N1[O]</smiles>

TEMPO<smiles>COc1cc(C(C)=O)cc(OC)c1O</smiles>

Acetosyringone

Figure 1 Structures of the mediators used in the study.

containing substrates. Palonen and Viikari [30] used T. hirsuta laccase with N-hydroxy-N-phenylacetamide (NHA) to treat steam pre-treated softwood prior to enzymatic hydrolysis and gained up to $21 \%$ improvement in the hydrolysis yield. The positive effect was considered to be due to the removal of lignin, but could also result from an expected modification of the surface lignin structure affecting enzyme-substrate interaction. In another study by Gutiérrez et al. four sequential laccase-HBT treatments followed by alkaline peroxide extraction of eucalyptus and elephant grass increased glucose yield by $61 \%$ with eucalyptus and $12 \%$ with elephant grass compared with those without enzymatic treatment [31]. The improvement of hydrolysis was attributed to a decrease of $34 \%$ and $22 \%$ in the lignin contents of eucalyptus and elephant grass, respectively. In addition, changes in the lignin structure were observed as a result of the laccase-HBT treatment. The share of G units appeared to decrease to a higher extent than that of the syringyl (S) units, leading to residual lignin consisting mostly of oxidized $\mathrm{S}$ units. In a further study by the same authors, similar improvements on the enzymatic hydrolysis of eucalyptus was gained when the Trametes villosa laccase was replaced with a recombinant Myceliophthora thermophila laccase and the synthetic HBT mediator was changed to a natural mediator; methyl syringate [32]. Heap et al., on the other hand, used laccase-HBT treatment in combination

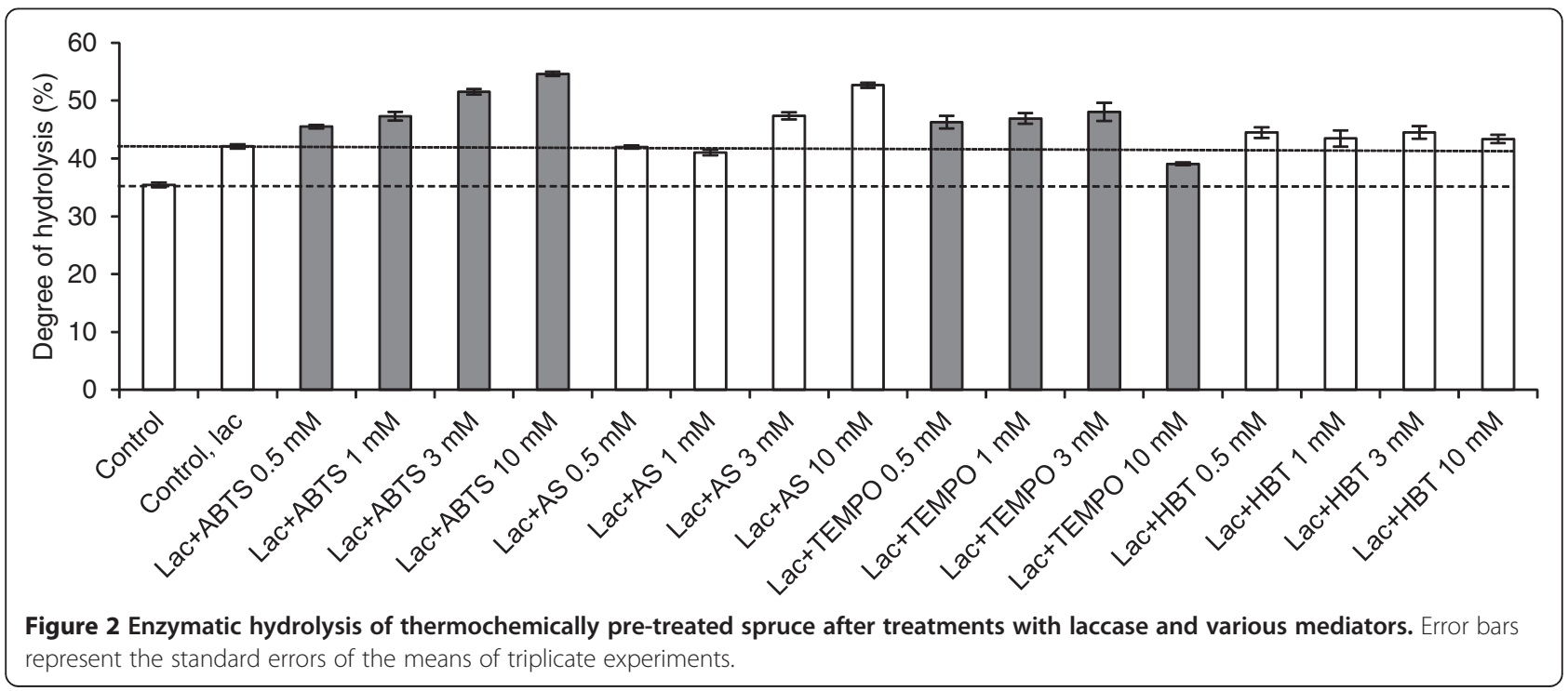


with alkaline peroxide extraction to improve (by 35\%) the saccharification yield of acid pre-treated wheat straw. It was observed that the LMT impaired the hydrolysis yield when not combined with the alkaline extraction step. The authors concluded that lignin extraction was enhanced by the LMT-induced formation of $\mathrm{C} \alpha$ oxidized groups in lig$\operatorname{nin}$ [33].

\section{Cellulose oxidation with LMTs}

To study the possible modification of cellulose structure by LMTs, phosphoric acid swollen cellulose (PASC) was treated with laccase and mediators (ABTS, HBT, TEMPO, or AS at $10 \mathrm{mM}$ concentration). Amorphous PASC was used as a model substrate because of its higher surface area and accessibility to oxidative reactions compared with the highly crystalline Avicel. To decrease the degree of polymerization and to solubilize the products, the treated PASC samples were enzymatically hydrolyzed. The hydrolyzed oxidation products were then analyzed with highperformance anion exchange chromatography with pulsed amperometric detection (HPAEC-PAD). Of the mediators examined, only TEMPO applied together with laccase produced peaks not found in the control samples. Thus, laccase-TEMPO treatment was the only treatment that oxidized PASC, suggesting that of the three possible mediated oxidation mechanisms, only the ionic oxidation mechanism was able to oxidize cellulose. After the laccase-TEMPO treatment followed by enzymatic hydrolysis, several unidentified elution peaks were observed in the chromatogram at 30 to $33 \mathrm{~min}$ and at 37 to $42 \mathrm{~min}$ (Figure 3a) when eluted with gradient 1 (Table 1). In an attempt to identify these oxidation products, the expected carbonyl (aldehyde) groups formed during laccase-TEMPO treatment were further oxidized to carboxyl groups by $\mathrm{NaClO}_{2}$ oxidation. Laccase-TEMPO treatment is known to oxidize the primary hydroxyl groups of cellulose to carbonyl and partially further to carboxyl groups at the C6 position, yielding 6-aldehydo-D-glucose and D-glucuronic acid units [34]. These compounds are further oxidized by $\mathrm{NaClO}_{2}$; the available free carbonyl groups, that is, the carbonyl group at the $\mathrm{C} 6$ position of the 6-aldehydo-Dglucose and the carbonyl group of the anomeric carbon (C1) of the D-glucose unit at the reducing end, are converted to carboxyl groups, yielding D-glucuronic acid and D-gluconic acid, respectively (Additional file 1: Figure S1). $\mathrm{NaClO}_{2}$ oxidation is known to oxidize carbonyl groups to carboxyl groups selectively, without oxidizing primary hydroxyls (at the C6 carbon) to carbonyls [35].

After $\mathrm{NaClO}_{2}$ oxidation, the peaks in the enzymatically hydrolyzed samples exhibited a clear shift from 30 to $33 \mathrm{~min}$ to 37 to $42 \mathrm{~min}$, indicating that peaks eluting at 30 to 33 min represented compounds with carbonyl groups and peaks eluting at 37 to 42 min represented compounds with the corresponding carboxyl groups (Figure 3b). No such peaks were found in the laccase-free control (Figure 3c), which confirms that they were not produced by TEMPO alone, by $\mathrm{NaClO}_{2}$ oxidation of glucose units, or by enzymatic hydrolysis. Recently, Patel et al. [36] also studied the oxidation of cotton linters pulp with various LMTs testing ABTS, HBT, TEMPO, violuric acid, and promazine as mediators for laccase. In agreement with the present study, it was found that only laccase-TEMPO treatment caused oxidative modification of cellulose. Selective labeling in combination with gel permeation chromatography was used to identify the oxidation products. It was concluded that the oxidized groups in the pulp were mostly carbonyl groups but carboxyl groups were also found. The results of the present study on the HPAEC-PAD analysis of the oxidized products of PASC by laccase-TEMPO treatment support these findings.

Oxidized groups in cellulose can prevent cellulases, especially cellobiohydrolases and $\beta$-glucosidases, from completely monomerizing cellulose. Therefore in the present study, the enzymatic hydrolysates were further hydrolyzed with mild acid to break down any possible oligomeric compounds (containing carbonyl or carboxyl groups) into monomeric units. Analysis of the oxidation products (after the enzymatic and mild acid hydrolysis of laccase-TEMPO and $\mathrm{NaClO}_{2}$-treated PASC samples) confirmed the formation of D-glucuronic acid eluting at 34 min when using HPAEC-PAD with gradient 1 (Figure $3 \mathrm{~d}$ and e), as confirmed by standards (Additional file 2: Figure S2). The concentration of D-glucuronic acid in the sample treated by laccase-TEMPO was $1.16 \mu \mathrm{mol} \mathrm{ml}^{-1}$, and after further oxidation with $\mathrm{NaClO}_{2}$ the concentration increased to $3.16 \mu \mathrm{mol} \mathrm{ml}{ }^{-1}$, corresponding to $2.6 \%$ of the total amount of glucose units, or on average every 40th glucose unit in cellulose being oxidized. As the degree of polymerization of Avicel (and thus of PASC) is in the range of 100 to 300 units, cellulose chains contained more than one oxidation site per polymer/cellulose chain. Furthermore, it can be anticipated that the oxidation of the primary hydroxyls happened at the most accessible areas of cellulose microfibrils, namely at the non-reducing ends of the cellulose chains and on cellulose chains located at the surface of cellulose microfibrils, where the oxoammonium ion had easy access.

After the mild acid hydrolysis of PASC treated with laccase-TEMPO and cellulases (but not with $\mathrm{NaClO}_{2}$ ), three significant peaks were detected (Figure 3d). One eluted at $34 \mathrm{~min}$, identified as D-glucuronic acid; for the identification of the two other peaks, eluting at $31 \mathrm{~min}$ and $39 \mathrm{~min}$, standards were lacking. After the $\mathrm{NaClO}_{2}$ oxidation, the height (and area) of the peaks of Dglucuronic acid (at $34 \mathrm{~min}$ ) and of the one appearing at 39 min increased considerably, and the peak at $31 \mathrm{~min}$ 

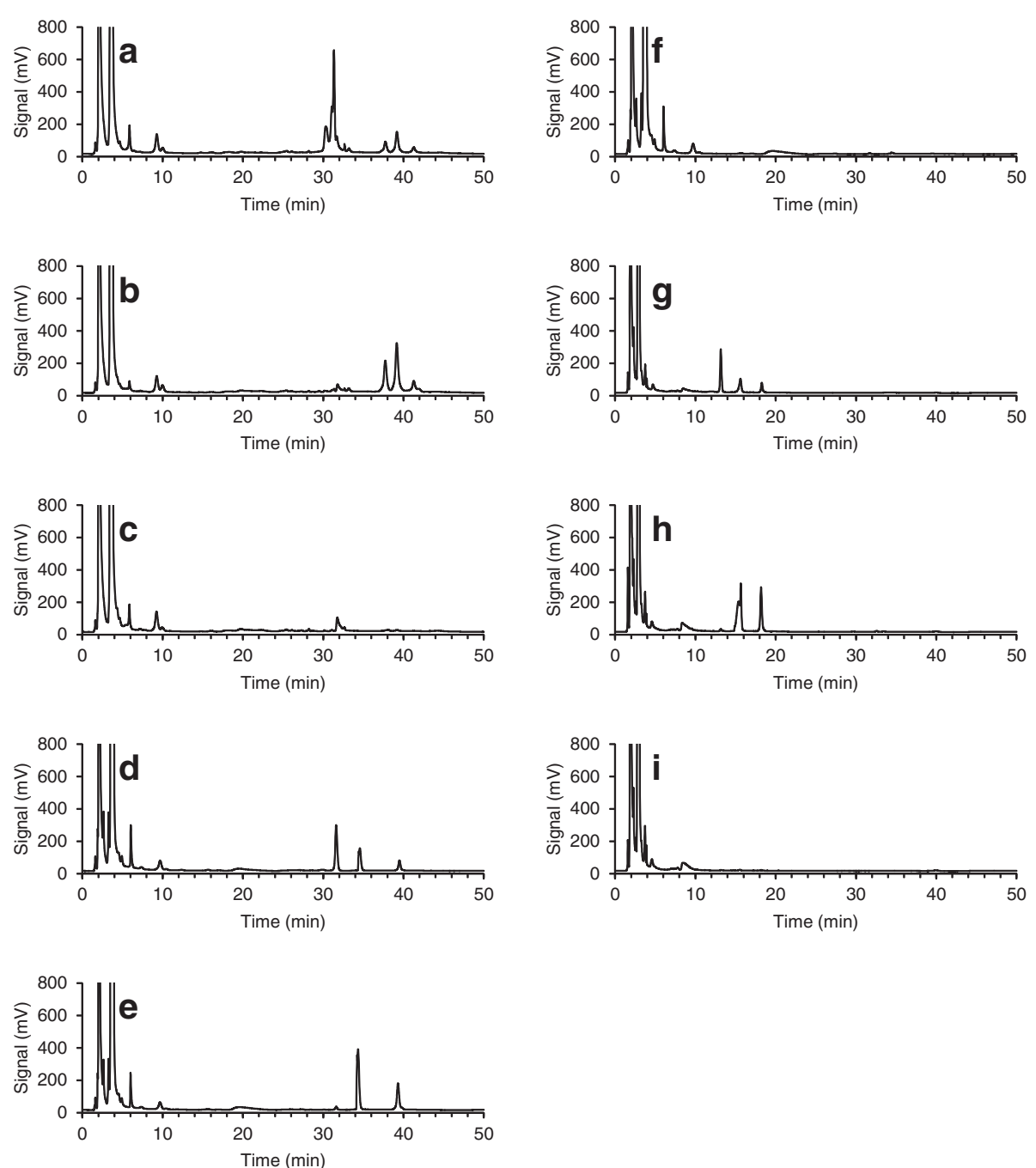

Figure 3 Analysis of the oxidation products of phosphoric acid swollen cellulose by HPAEC-PAD after laccase-TEMPO treatment. (a) Laccase-TEMPO treatment (LTT) and enzymatic hydrolysis (EH); (b) LTT, $\mathrm{NaClO}_{2}$ oxidation, and EH; (c) TEMPO treatment, $\mathrm{NaClO}_{2}$ oxidation, and EH; (d) $\mathrm{LTT}, \mathrm{EH}$, and acid hydrolysis (AH); (e) $\mathrm{LTT}, \mathrm{NaClO}_{2}$ oxidation, $\mathrm{EH}$, and $\mathrm{AH}$; (f) TEMPO treatment, $\mathrm{NaClO}_{2}$ oxidation, $\mathrm{EH}$, and $\mathrm{AH} ;(\mathbf{g}) \mathrm{LTT}$, EH, and $\mathrm{AH}$; (h) LTT, $\mathrm{NaClO}_{2}$ oxidation, EH, and AH; (i) TEMPO treatment, $\mathrm{NaClO}_{2}$ oxidation, EH, and AH. (a-c) Diluted 1:5; (d-f) diluted 1:2; (a-f) eluted with gradient $1 ;$ (g-i) eluted with gradient 2 .

Table 1 The gradients used in the HPAEC-PAD analysis for oligosaccharides

\begin{tabular}{lllllll}
\hline Gradient 1 & & & & Gradient 2 & \\
\cline { 1 - 2 } Time (min) & A (\%) & B (\%) & & Time (min) & A (\%) & B (\%) \\
\hline 0 & 0 & 100 & & 0 & 2 & 98 \\
15 & 0 & 100 & & 30 & 30 & 70 \\
35 & 12 & 88 & 35 & 30 & 70 \\
40 & 12 & 88 & 40 & 2 & 98 \\
45 & 0 & 100 & 50 & 2 & 98 \\
50 & 0 & 100 & & & \\
\hline
\end{tabular}

A: $1 \mathrm{M} \mathrm{NaAc}$ in $100 \mathrm{mM} \mathrm{NaOH}$; B: $100 \mathrm{mM} \mathrm{NaOH}$. disappeared (Figure 3e). This indicates that the 31-min peak was 6-aldehydo-D-glucose being oxidized to Dglucuronic acid (34 min) with $\mathrm{NaClO}_{2}$. Furthermore, the increase in the size of the third peak (at $39 \mathrm{~min}$ ) indicates that it was a compound with a higher degree of oxidation. None of these oxidation products was present in the laccase-free control (Figure 3f).

To identify the unknown peak eluting at $39 \mathrm{~min}$, the $\mathrm{NaClO}_{2}$-oxidized samples were analyzed again with the HPAEC-PAD system with gradient 2 (Table 1 and Figure 3 g-i). This time a new peak appeared at around $8 \mathrm{~min}$ and was identified by a standard as D-gluconic acid (Additional file 2: Figure S2). With this type of analysis, the D-gluconic acid peak was flat and wide and therefore difficult to detect. By altering the gradient, the D-gluconic acid peak 
could be detected more accurately in samples subjected to enzymatic and mild acid hydrolysis after laccaseTEMPO treatment (Figure 3g, around 20 min in Figure 3d). However, the signal-to-noise ratio was too low to confirm unambiguously the formation of $\mathrm{D}$-gluconic acid by laccase-TEMPO treatment. On the other hand, D-gluconic acid was clearly formed by chemical oxidation (Figure $3 \mathrm{~h}$ and i). $\mathrm{NaClO}_{2}$ oxidized not only the 6-aldehydo-D-glucose to $\mathrm{D}$-glucuronic acid but also the unprotected $\mathrm{C} 1$ carbonyl at the reducing end of the cellulose chain to D-gluconic acid. Notably, when the samples were eluted with gradient 2 , the peak assigned to D-glucuronic acid (15 min, Figure $3 \mathrm{~h}$ ) split into two overlapping peaks, indicating that another compound co-eluted. L-guluronic acid is expected to elute very closely to D-glucuronic acid on the HPAECPAD column due to their similar structures (Additional file 1: Figure S1). If the laccase-TEMPO treatment oxidized glucose units located at the reducing end of cellulose to 6aldehydo-D-glucose, then two products could be formed upon further oxidization: D-glucuronic acid (6-aldehydoD-glucose oxidized at the C6 position) and L-guluronic acid (6-aldehydo-D-glucose oxidized at the $\mathrm{C} 1$ position). In fact, oxidation at the reducing end could also explain the third unassigned peak (39 $\mathrm{min}$ in Figure $3 \mathrm{~d}$ and e or $18 \mathrm{~min}$ in Figure 3g and h), which would then be dicarboxylic acid, that is, D-glucaric acid, being formed at the reducing end by further oxidation of the carbonyl group of either D-glucuronic acid or L-guluronic acid to a carboxylic group.

In conclusion, of the mediators studied, only TEMPO was able to oxidize PASC when combined with laccase. The possible oxidation products of $\mathrm{D}$-glucose units by laccase-TEMPO treatment are shown in Additional file 1: Figure S1. Laccase-TEMPO treatment of PASC oxidized D-glucose units primarily at the C6-position, mostly at the non-reducing ends of the cellulose chain and on the surface of cellulose microfibrils, forming 6-aldehydo-Dglucose. In addition, some of these aldehydes were further oxidized to D-glucuronic acid. Furthermore, the results indicate that laccase-TEMPO treatment can lead to the oxidation of reducing end D-glucose units at the C6 position, allowing $\mathrm{NaClO}_{2}$ to oxidize the 6-aldehydo-D-glucose unit further to D-glucuronic, L-guluronic, and D-glucaric acids. Chromatographic data suggests the formation of Dgluconic acid and D-glucaric acid (Figure 3d and g) by oxidation solely with laccase-TEMPO treatment. Accordingly, the oxidation of free carbonyl groups of the anomeric carbon at the reducing end of cellulose to carboxyl groups by laccase-TEMPO treatment is also likely and cannot be excluded, as the commercial cellulase preparation used (Celluclast 1.5L) lacks oxidative cellulosedegrading enzymes.

To study the impact of the cellulose oxidation on the enzymatic hydrolysis of cellulose, Avicel was treated with laccase and TEMPO and further hydrolyzed with the commercial cellulase preparation (Figure 4). Notably, on the pure cellulose substrate Avicel, a low mediator concentration already had an adverse effect on the degree of hydrolysis. Increasing the mediator concentration impaired the degree of hydrolysis, obviously due to a growing number of oxidation sites. When the concentration of TEMPO was increased to $10 \mathrm{mM}$ the degree of hydrolysis declined from 33 to $21 \%$. The formation of carbonyl and carboxyl groups on Avicel can be expected to especially inhibit the action of cellobiohydrolases and $\beta$-glucosidases, as they act on chain ends and cellooligomers, respectively. In addition, inter-fiber covalent bonds through hemiacetal linkages between hydroxyl groups and carbonyl groups may have been formed after the laccase-TEMPO treatment, increasing the strength of the cellulose [35]. To confirm that the inhibition of the hydrolysis was caused by cellulose oxidation and not by the interaction of oxidized TEMPO with cellulases, an additional experiment was performed: Avicel, oxidized by laccase and $(10 \mathrm{mM})$ TEMPO, was washed three times with $5 \mathrm{ml}$ of ultrapure water prior to the enzymatic hydrolysis step to remove residual laccases and oxidized TEMPO that might affect the performance of the hydrolytic enzymes. Again, the hydrolysis yield was reduced from 33 to $17 \%$, verifying that cellulose oxidation was the cause of the hydrolysis impairment (Figure 4).

Thus, it is significant that even though the treatment of Avicel by $3 \mathrm{mM}$ laccase-TEMPO clearly inhibited hydrolysis, the degree of hydrolysis was improved when SPS was used as a substrate. These results indicate that the positive effects on lignin caused by the treatment outweighed the negative effects on cellulose or that the

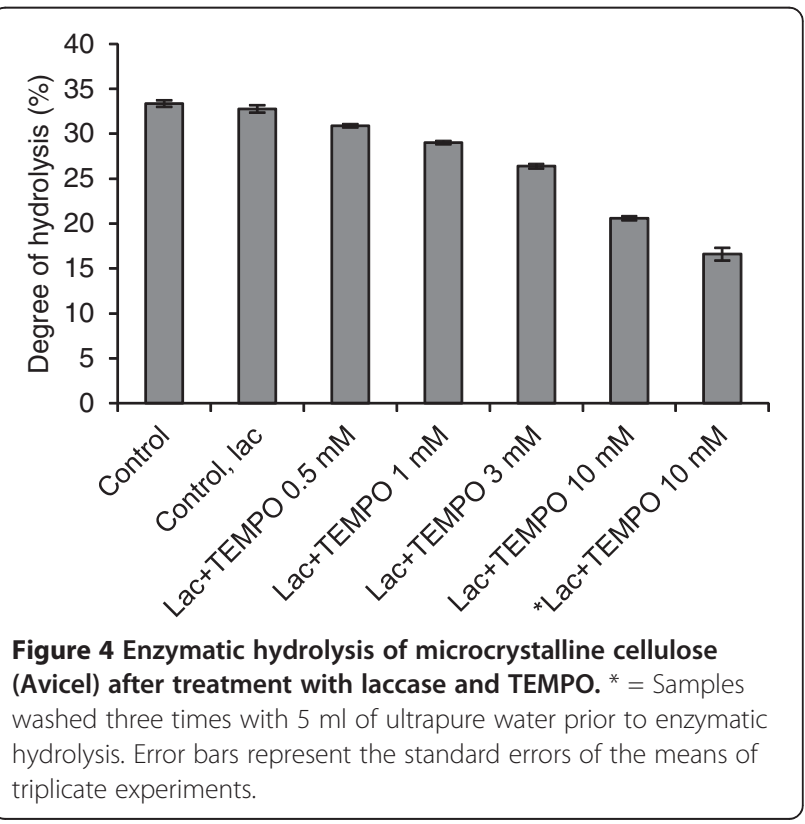


oxidative systems preferably attacked lignin. When the TEMPO concentration was increased to $10 \mathrm{mM}$ on SPS, the oxidation of cellulose was the determining factor in reducing the degree of hydrolysis. Previously, the oxidation of cellulose by lytic polysaccharide monooxygenases has been observed to improve the hydrolysis of cellulose. It has been concluded that the positive effect is due to the oxidation of the $\mathrm{C} 1$ or $\mathrm{C} 4$ position in the $\mathrm{D}$-glucose units, causing the cleavage of the $\beta-1,4$ linkage in the cellulose chain [37]. Notably, as opposed to the laccaseTEMPO treatment, the action of lytic polysaccharide monooxygenases leads to the formation of two new cellulose chain ends, one oxidized and one non-oxidized, increasing the number of sites available for the action of cellobiohydrolases.

\section{Effect of LMTs on SPS lignin}

As the oxidation of cellulose hinders the hydrolytic action of cellulases (Figure 4), the positive effects of oxidative treatments on SPS hydrolysis (Figure 2) can be expected to have been caused by the modification of lignin. Cellulases are known to adsorb non-specifically to lignin [4], and thus oxidative modification may affect the binding properties of lignin. The adsorption properties of a mixture of purified enzymes (70\% Trichoderma reesei Cel7A, 25\% T. reesei Cel5A, and 5\% Aspergillus niger Cel3A) to isolated SPS lignin were assessed using the Langmuir isotherm (Eq. 1). Cel7A and Cel5A are among the main components in Celluclast 1.5L, whereas Cel3A is the $\beta$-glucosidase present in Novozym 188. The maximum adsorption capacity of SPS lignin was $55 \mathrm{mg}$ pro-

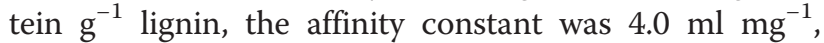
and the binding strength was $220 \mathrm{ml} \mathrm{g}^{-1}$ lignin. These values are somewhat higher than previously reported for spruce lignin. For example, Rahikainen et al. [38] determined the Langmuir isotherms for similarly treated and isolated spruce lignin using Melanocarpus albomyces Cel45A endoglucanase fused with a linker and a carbohydrate binding module from $T$. reesei Cel7A. In that study, the maximum adsorption capacity was $42 \mathrm{mg}$ protein $\mathrm{g}^{-1}$ lignin, the affinity constant $1.5 \mathrm{ml} \mathrm{mg}^{-1}$, and the binding strength $64 \mathrm{ml} \mathrm{g}^{-1}$ lignin. Previously, adsorption experiments with Cel45A were performed at $4^{\circ} \mathrm{C}$, whereas the enzyme mixture used in this study was adsorbed at $45^{\circ} \mathrm{C}$. Adsorption of Celluclast $1.5 \mathrm{~L}$ on isolated spruce lignin has been reported to increase when the temperature is raised from $4^{\circ} \mathrm{C}$ to $45^{\circ} \mathrm{C}$. Furthermore, the enzymes have been observed to have stronger interaction with SPS lignin at elevated temperatures [9], which would explain the differences observed in the Langmuir isotherms.

To study the effects of various oxidative treatments by laccase and mediators on the non-specific binding of the enzymes on lignin, isolated SPS lignin was treated with laccase and $10 \mathrm{mM}$ mediators. To observe clearly the differences in adsorption caused by the treatments, the concentration of the cellulase mixture used was $50 \mathrm{mg} \mathrm{g}^{-1}$, which is lower than the maximum adsorption capacity of untreated SPS lignin. Under these conditions, the untreated SPS lignin bound more than half of the cellobiohydrolase Cel7A, leaving $44 \%$ of the proteins free in the solution (Figure 5a). Treating SPS lignin with laccase alone decreased the binding of Cel7A by $27 \%$. The adsorption of Cel7A was further decreased by supplementing a mediator. Of the mediators used, ABTS changed the binding properties of the SPS lignin most considerably, increasing
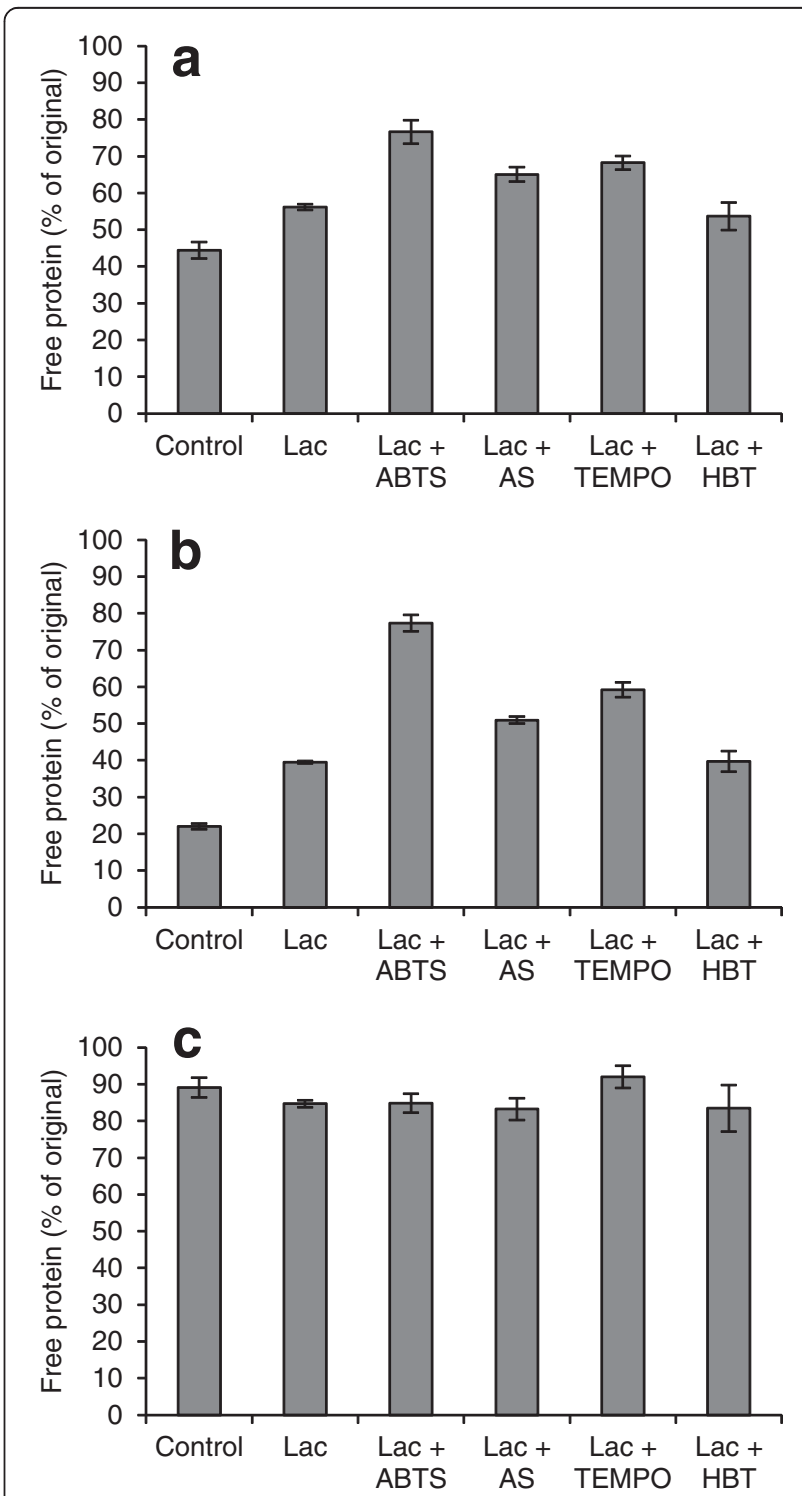

Figure 5 Adsorption of purified cellulases on the isolated laccase- and mediator-treated SPS lignins. (a) Cellobiohydrolase Cel7A, (b) endoglucanase Cel5A, and (c) $\beta$-glucosidase Cel3A. Error bars represent the standard errors of the means of triplicate experiments. 
the share of free Cel7A to 77\%. AS and TEMPO also decreased the non-specific binding of Cel7A on lignin: after the treatments, $65 \%$ and $68 \%$ of the protein remained unbound, respectively. Notably, the impact caused by the oxidative treatments was even more substantial on the endoglucanase Cel5A (Figure 5b). The Cel5A was bound to the untreated lignin to a higher degree than Cel7A. The same phenomenon has also been observed previously with T. reesei cellulases [29]. The laccase treatment changed the binding properties of the lignin by increasing the percentage of free Cel5A from 22 to $40 \%$. As with Cel7A, the laccase-ABTS treatment had the most notable effect on the binding of Cel5A by increasing the share of free enzyme to $77 \%$. Again, the laccase-TEMPO and laccase-AS treatments also decreased the adsorption of Cel5A compared with the control. On the other hand, laccase-HBT treatment of lignin did not affect the binding of any of the enzymes in the mixture compared with the mediatorfree laccase control. As anticipated, the adsorption of $\beta$ glucosidase did not change after the treatments (Figure 5c), since most of the enzymes remained free even after incubation with untreated SPS lignin. Observations on the binding of cellulases on lignin after LMT have not been previously described.

The inability of the laccase-HBT treatment to improve the hydrolysis of SPS (Figure 2) was explained by the unchanged binding properties of laccase-HBT treated lignin (Figure 5), and raised the question of whether HBT is a suitable substrate for the T. hirsuta laccase. To confirm that $T$. hirsuta laccase was able to oxidize HBT, the oxygen consumption of laccase and HBT was measured. It was observed that oxygen was consumed 40 times more slowly with HBT than with the other mediators (Additional file 3: Figure S3). In other words, HBT was not an optimal substrate for $T$. hirsuta laccase. Bourbonnais et al. [39] noticed the same phenomenon when the oxygen consumption of Trametes versicolor laccase was measured with ABTS or HBT. It was reported that the oxidation of HBT by laccase was more than 85 times slower than the oxidation of ABTS. In addition, it was observed that during pulp delignification, $\mathrm{HBT}$ inactivated the $T$. veriscolor laccase almost completely, whereas when using ABTS, $32 \%$ of the initial laccase activity was recovered.

In addition to the ability of LMTs to modify the cellulase binding properties of lignin, the treatments may also have changed the lignin contents of the treated samples. To study these changes, both soluble and insoluble lignins were analyzed. The modifications of soluble aromatic compounds were detected by measuring the UV absorbance spectrum (220 to $400 \mathrm{~nm}$ ) from the liquid fractions of enzymatically hydrolyzed SPS samples treated first with laccase and $3 \mathrm{mM}$ mediators (Figure 6). Enzymatic hydrolysates of SPS without LMT or laccase-treated samples (lacking mediators) were used as reference. In addition, a combined reference curve was calculated from the reference samples of enzymatic hydrolysates of untreated SPS and samples incubated with laccase and mediator in the absence of SPS. The solid lignin content, on the other hand, was determined by the Klason lignin method from the SPS samples after the LMTs (Table 2).

Laccase treatment alone reduced the total amount of soluble aromatic compounds in the liquid fraction (Figure 6) and increased the lignin content of the solid fraction (Table 2), which indicates that laccase polymerized solubilized aromatic compounds on lignin. The same has been previously observed when SPS was treated with Cerrena unicolor laccase [29]. Of the studied mediators, ABTS, when applied together with laccase, was the only mediator able to solubilize some of the SPS lignin. According to the Klason lignin determination (Table 2), $4 \%$ of the acid insoluble lignin was solubilized, which was also visible in the UV spectra of the liquid fractions as an increase of the absorbance at 245 to $295 \mathrm{~nm}$ compared with the control (Figure 6a). The inability of the LMTs to solubilize significant amounts of SPS lignin can be caused by the insolubility of lignin in aqueous solutions [40]. In other words, the LMTs could potentially degrade lignin, but the fragments would not be soluble in a pH 5 buffer. Thus, LMTs are more likely to cause modifications of the surface lignin, observed as changes in the adsorptions of cellulases (Figure 5), rather than to cause lignin dissolution. It is also possible that aromatic fragments solubilized from lignin by laccase and ABTS may have acted as mediator(s) for further lignin modification employing the HAT mechanism typical for lignin-derived mediators [26], which would explain the remarkable improvements in the enzymatic hydrolysis yield (Figure 2) and the decreased enzyme adsorption (Figure 5).

Notably, laccase appeared to polymerize AS on the lignin, which was observed as an increase in the lignin content (Table 2) and as a decrease of aromatic compounds in the UV absorbance spectra (Figure 6b). In previous delignification studies using LMTs, it has been observed that natural phenolic mediators have a tendency to bind to lignin rather than to dissolve it [26]. It might be that the improvement of the enzymatic hydrolysis (Figure 2) and the change in the enzyme adsorption (Figure 5) was a result of the S-type AS covering the G-type spruce lignin surface, which thus contained a higher portion of S-type moieties after the treatment. Studer et al. [41] studied the enzymatic hydrolysis of 47 Populus trichocarpa tree samples. The trees were selected out of 1,100 individuals on the basis of the content and ratio of $\mathrm{S}$ and $\mathrm{G}$ units in lignin. They observed that the sugar yields increased with increasing S/G ratios. Furthermore, Nakagame et al. [10] showed that GS-type lignin isolated from poplar adsorbed fewer cellulases than G-type lignin isolated from lodgepole pine. Thus, the two types of lignins appear to have different cellulase binding properties, which was also apparent in the present study. 

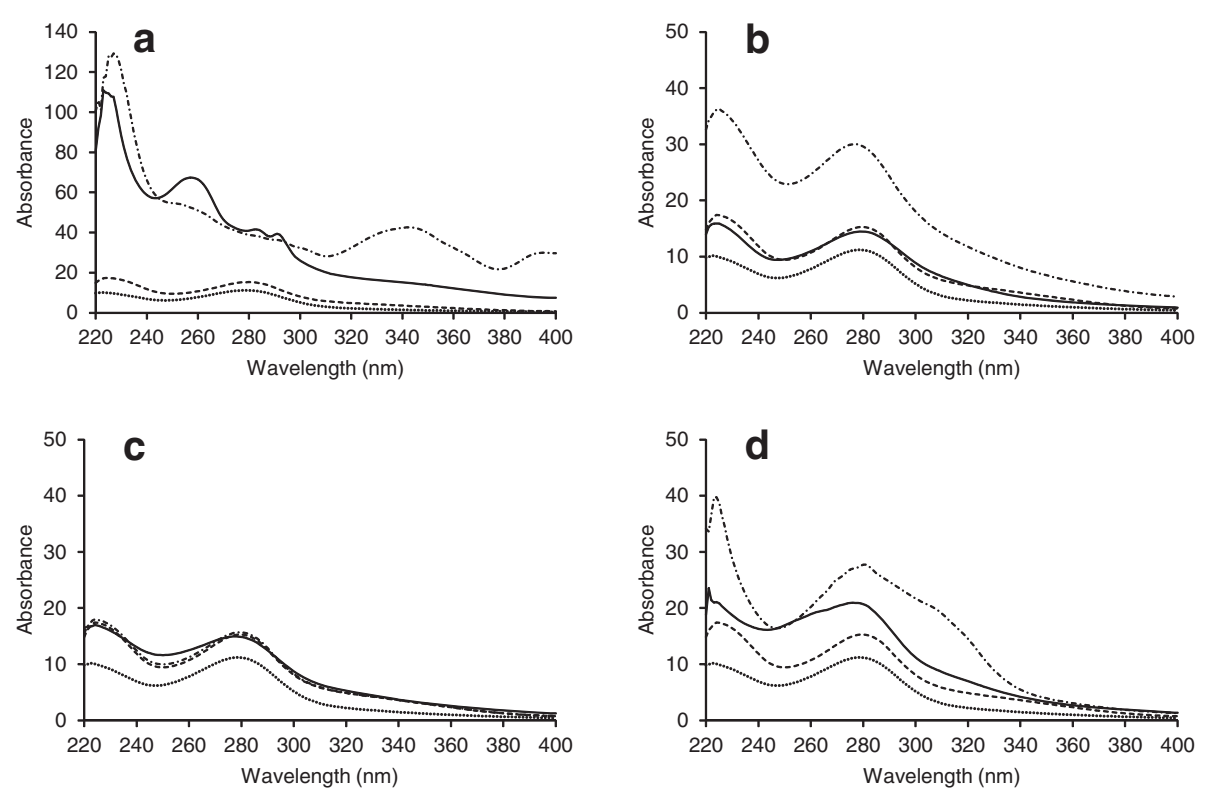

Figure 6 The modification of soluble aromatic compounds of SPS caused by laccase-mediator treatment. UV absorbance spectrum (220 to $400 \mathrm{~nm}$ ) was measured from the liquid fractions of enzymatically hydrolyzed SPS samples treated with laccase and 3 mM mediators. Mediators used were (a) ABTS, (b) AS, (c) TEMPO, and (d) HBT. Dashed line = reference enzymatic hydrolysis (lacking laccase-mediator treatment), dotted line $=$ reference laccase treatment followed by enzymatic hydrolysis (lacking mediator), dash-dotted line $=$ combined curve of reference enzymatic hydrolysis (lacking laccase-mediator treatment) and reference laccase and mediator (lacking SPS), and solid line = laccase-mediator treatment followed by enzymatic hydrolysis.

Laccase-HBT and laccase-TEMPO treatments did not change the amount of lignin in the solid fractions significantly (Table 2). Obviously, however, the laccase-TEMPO treatment modified the surface properties of the lignin in SPS, leading to reduced binding of cellulases (Figure 5) and, despite the adverse effect of laccase-TEMPO treatment on the enzymatic hydrolysis of cellulose (Figure 4), improved the enzymatic hydrolysis of SPS (Figure 2).

\section{Conclusions}

The improving mechanism of LMTs on the enzymatic hydrolysis of SPS was based on the modification of the SPS lignin, resulting in decreased adsorption of cellulases on lignin and increased hydrolysis yields. On the other hand, cellulose oxidation by laccase-TEMPO treatment was

Table 2 Lignin content in SPS after laccase and $10 \mathrm{mM}$ mediator treatments

\begin{tabular}{lll}
\hline & Acid insoluble lignin (\%) & Acid soluble lignin (\%) \\
\hline Control & $44.4 \pm 0.7$ & $1.0 \pm 0.0$ \\
Laccase & $45.9 \pm 0.2$ & $0.9 \pm 0.1$ \\
Laccase + ABTS & $42.5 \pm 0.5$ & $1.6 \pm 0.0$ \\
Laccase + AS & $47.7 \pm 0.6$ & $1.5 \pm 0.1$ \\
Laccase + TEMPO & $43.9 \pm 0.4$ & $1.0 \pm 0.1$ \\
Laccase + HBT & $44.2 \pm 0.2$ & $1.3 \pm 0.0$ \\
\hline
\end{tabular}

Errors calculated as the standard errors of the means of triplicate experiments. observed to impair the enzymatic hydrolysis of cellulose. For future applications, it would be beneficial to be able to understand and modify the binding properties of lignin in order to decrease unspecific enzyme binding and thus to increase the mobility, action, and recyclability of the hydrolytic enzymes.

\section{Methods}

\section{Raw materials}

Spruce chips were impregnated with $\mathrm{SO}_{2}$ gas (residence time $13 \mathrm{~min}$ ) and steam pre-treated at $212^{\circ} \mathrm{C}$ for 4 to $5 \mathrm{~min}$. The SPS provided by Sekab E-Technology (Sweden) was washed three times with $80^{\circ} \mathrm{C}$ water before use. The SPS lignin was isolated as described in Moilanen et al. [29] by an extensive enzymatic hydrolysis [8], and the bound hydrolytic enzymes were removed with a protease treatment [42]. Microcrystalline cellulose Avicel (Fluka, Ireland) and PASC were used as cellulose model compounds. PASC was prepared from Avicel by modifying Wood's method [43]. Avicel $(25 \mathrm{~g})$ was slowly added to $400 \mathrm{ml}$ of $85 \%\left(\mathrm{~V} \mathrm{~V}^{-1}\right)$ phosphoric acid at $4{ }^{\circ} \mathrm{C}$, as the mixture was blended in a kitchen homogenizer. The solution was incubated at $4^{\circ} \mathrm{C}$ overnight. PASC was extensively washed with ultrapure water until the $\mathrm{pH}$ of the supernatant was 5. The last wash was performed with $100 \mathrm{mM}$ sodium acetate buffer, $\mathrm{pH}$, and the PASC was stored at $4^{\circ} \mathrm{C}$. 


\section{Enzymes and mediators}

Laccase from T. hirsuta was produced and purified as described in Rittstieg et al. [44]. The hydrolytic enzymes used were cellulases from $T$. reesei (Celluclast 1.5L, Novozymes, Denmark) and $\beta$-glucosidase from A. niger (Novozym 188, Novozymes, Denmark). The monocomponent cellulases cellobiohydrolase Cel7A (EC 3.2.1.91) and endoglucanase Cel5A (EC 3.2.1.4) from T. reesei were purified according to Suurnäkki et al. [45] and the $\beta$-glucosidase Cel3A (EC 3.2.1.21) from A. niger by the method described in Sipos et al. [46]. Four commercial compounds - TEMPO (Aldrich, Poland), HBT (Sigma, Japan), ABTS (Sigma, Canada), and AS (Aldrich, India) - were used as mediators. The mediators were dissolved in $100 \mathrm{mM}$ sodium acetate bufferethanol solution $\left(1: 1 \mathrm{~V} \mathrm{~V}^{-1}\right)$. A fresh batch of the mediator solutions was prepared for each experiment.

\section{Laccase activity assay}

Laccase activity was determined using ABTS as substrate, according to Niku-Paavola et al. [47].

\section{Determination of protein concentration}

Protein concentration was determined by the Lowry method [48] (absolute protein concentrations) or with gel electrophoresis (relative protein concentrations) using the Criterion Stain Free Imager (Bio-Rad, USA) system described in Várnai et al. [49]. With the Lowry method, interfering substances were eliminated by precipitating the proteins with acetone (1:4 ratio of protein solution to acetone). The precipitate was dissolved in a solution containing $\mathrm{Na}_{2} \mathrm{CO}_{3}(2 \%)$ and $\mathrm{NaOH}(0.4 \%)$ before measurement. Bovine serum albumin (Sigma, USA) was used as the standard in the Lowry method, while the mixture of pure enzymes was used as the standard in the quantification with gel electrophoresis.

\section{Carbohydrate analysis}

Monosaccharides were determined with the HPAECPAD system as described by Moilanen et al. [29]. The cellulose oxidation products were also analyzed with an HPAEC-PAD system according to the method described by Rantanen et al. [50] for analysis of oligosaccharides. The eluents for gradient analysis of the oxidation products were A: $1 \mathrm{M} \mathrm{NaAc}$ in $100 \mathrm{mM} \mathrm{NaOH}$ and B: $100 \mathrm{mM}$ $\mathrm{NaOH}$. The samples were analyzed with two different gradients named gradient 1 and gradient 2 (Table 1). DGluconic acid sodium salt (Sigma, France), D-glucuronic acid (Sigma, Switzerland), and a cellooligosaccharide standard containing cellobiose, cellotriose, and cellotetraose (Merck, Germany) were used as standards.

\section{Determination of lignin content}

The dissolved SPS lignin was determined by measuring the UV absorption spectrum (220 to $400 \mathrm{~nm}$ ) spectrophotometrically from liquid samples, whereas the solid SPS lignin was determined by the Klason lignin method according to Sluiter et al. [51]. In this method, the samples were hydrolyzed with sulfuric acid and the acid insoluble lignin was determined from the solid residue, while the acid soluble lignin was measured from the hydrolysate spectrophotometrically at $240 \mathrm{~nm}$ using an absorptivity of $30 \mathrm{l}(\mathrm{g} \mathrm{cm})^{-1}[52,53]$.

\section{LMTs and enzymatic hydrolysis}

LMTs were performed on SPS and Avicel at a substrate consistency of $2 \%\left(\mathrm{w} \mathrm{V}^{-1}\right)$ dry matter (DM), in $100 \mathrm{mM}$ sodium acetate buffer, $\mathrm{pH} 5$, in $2 \mathrm{ml}$ reaction volume, at $45^{\circ} \mathrm{C}$, and $250 \mathrm{rpm}$ shaking for $24 \mathrm{~h}$. Laccase was added

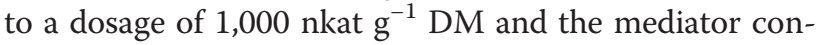
centrations were $0.5,1,3$, and $10 \mathrm{mM}$. Untreated, laccase-treated, and mediator-treated samples were used as controls. After the treatments, laccase activity was terminated by boiling $(10 \mathrm{~min})$, and the hydrolytic enzymes Celluclast $1.5 \mathrm{~L}\left(10 \mathrm{mg} \mathrm{g}^{-1} \mathrm{DM}\right)$ and Novozym 188 (500 nkat g ${ }^{-1}$ DM) were added, together with $\mathrm{NaN}_{3}$ $\left(0.02 \%\left(\mathrm{w} \mathrm{V}^{-1}\right)\right.$ final concentration) to avoid microbial contamination. The hydrolysis was continued for $24 \mathrm{~h}$. Liquid fractions containing the released sugars were separated from solid residues by centrifugation. The released sugars were analyzed with HPAEC-PAD and the results were calculated as the degree of hydrolysis (\%) of the theoretical carbohydrate yield. All the hydrolysis experiments were run in triplicate. The values reported are the means of the triplicate experiments, and the errors were calculated as the standard errors of the means.

To detect the dissolved SPS lignin, the UV absorption spectrum (220 to $400 \mathrm{~nm}$ ) was measured spectrophotometrically from the liquid fractions of enzymatically hydrolyzed samples treated first with laccase and $3 \mathrm{mM}$ mediators. Mediators oxidized by laccase without substrate were used as controls. In addition, the solid lignin content was determined from SPS samples treated with laccase and $10 \mathrm{mM}$ mediators (but not with hydrolytic enzymes). Untreated and laccase-treated samples were used as controls. The values reported are the means of triplicate experiments, and the errors were calculated as the standard errors of the means.

\section{Cellulose oxidation}

Cellulose oxidation was studied using PASC as the substrate. LMTs were carried out as described in the previous section. The laccase dosage used was 5,000 nkat g ${ }^{-1}$ $\mathrm{DM}$, and the mediator concentration was $10 \mathrm{mM}$. To identify the carbonyl groups formed in LMT, some of the LMT samples were further oxidized chemically to 
the corresponding carboxyls using a method modified from Saito and Isogai [35] by adding $0.2 \mathrm{ml}$ of $2 \mathrm{M}$ $\mathrm{NaClO}_{2}, 0.4 \mathrm{ml}$ of $5 \mathrm{M}$ acetic acid, and $0.4 \mathrm{ml}$ of ultrapure water to washed LMT PASC. The oxidation reaction was carried out for $48 \mathrm{~h}$ at room temperature $\left(23^{\circ} \mathrm{C}\right)$ in tubes with magnetic stirring. After incubation, the modified cellulose was washed three times with $5 \mathrm{ml}$ ultrapure water and separated from the liquid fraction by centrifugation.

For analysis of the oxidized products, samples treated by laccase and mediators and by laccase and mediators and $\mathrm{NaClO}_{2}$ oxidation were enzymatically hydrolyzed into soluble sugars with Celluclast $1.5 \mathrm{~L}\left(40 \mathrm{mg} \mathrm{g}^{-1} \mathrm{DM}\right.$ of substrate) and Novozym 188 (1,000 nkat $\left.\mathrm{g}^{-1} \mathrm{DM}\right)$. The hydrolysis was carried out as described in the previous section. Some of the samples were further hydrolyzed by dilute acid hydrolysis modified from Sluiter et al. [51] by adding $2 \mathrm{ml}$ of sample and $100 \mu \mathrm{l}$ of $70 \%$ $\mathrm{H}_{2} \mathrm{SO}_{4}$ to a 5 - $\mathrm{ml}$ volumetric flask. The samples were autoclaved for $1 \mathrm{~h}$ at $120^{\circ} \mathrm{C}$, and after cooling the $\mathrm{pH}$ was adjusted to 7 and the volume to $5 \mathrm{ml}$. Untreated, mediator-treated, laccase-treated, and $\mathrm{NaClO}_{2}$-oxidized PASC were used as controls.

\section{Adsorption experiments}

Protein adsorption experiments were performed on the isolated SPS lignin treated with laccase and mediators. The treatment was carried out at a lignin concentration of $1 \%\left(\mathrm{w} \mathrm{V}^{-1}\right) \mathrm{DM}$ (corresponding to $2 \% \mathrm{DM}$ of SPS), in $100 \mathrm{mM}$ sodium acetate buffer, $\mathrm{pH} 5$, at $45^{\circ} \mathrm{C}$, and $250 \mathrm{rpm}$ shaking for $24 \mathrm{~h}$. Laccase was added to a dosage of 2,000 nkat $\mathrm{g}^{-1} \mathrm{DM}$, and the mediator concentration was $10 \mathrm{mM}$. After the treatments, laccase activity was terminated by boiling (10 $\mathrm{min}$ ), and solids were separated by centrifugation and washed three times with $\mathrm{pH}$-adjusted ultrapure water $(\mathrm{pH}$ adjusted to 2.5 with $\mathrm{HCl})$. Untreated and laccase-treated lignins were used as controls and were subjected to the same treatment conditions as the LMT lignins. All lignins were lyophilized and stored at room temperature.

The adsorption was carried out at a lignin concentration of $1 \%\left(\mathrm{w} \mathrm{V}^{-1}\right) \mathrm{DM}$, in $100 \mathrm{mM}$ sodium acetate buffer, in a reaction volume of $1.5 \mathrm{ml}, \mathrm{pH} 5$, at $45^{\circ} \mathrm{C}$, and $250 \mathrm{rpm}$ shaking for $90 \mathrm{~min}$. The lignins were incubated with a mixture of purified enzymes, which contained (on a weight basis) $70 \%$ T. reesei Cel7A, 25\% T. reesei Cel5A, and $5 \%$ A. niger Cel3A. Controls lacking lignins or enzymes were used. The free proteins in the samples were quantified with gel electrophoresis using Bio-Rad's Criterion Stain Free Imager system.

To determine the adsorption parameters, the untreated SPS lignin was incubated with $10-200 \mathrm{mg} \mathrm{g}^{-1}$ $\mathrm{DM}$ of the enzyme mixture. The adsorption parameters were determined by the non-linear regression of the adsorption data using the Langmuir isotherm:

$$
P_{a}=P_{a, \max } \frac{K_{P} P_{f}}{1+K_{P} P_{f}}
$$

where $P_{a}$ is the amount of adsorbed protein $(\mathrm{mg}$ protein $\mathrm{g}^{-1}$ substrate), $P_{a, \max }$ is the maximum adsorption capacity (mg protein $\mathrm{g}^{-1}$ substrate), $K_{p}$ is the affinity constant $\left(\mathrm{ml} \mathrm{mg}^{-1}\right.$ protein), and $P_{f}$ is the concentration of free protein (mg protein $\left.\mathrm{ml}^{-1}\right)$. The binding strength ( $\mathrm{ml} \mathrm{g}^{-1}$ substrate) is defined as:

$$
S=P_{a, \max } K_{P}
$$

For the laccase-treated and LMT lignins the enzyme mixture concentration used was $50 \mathrm{mg} \mathrm{g}^{-1} \mathrm{DM}$. The values reported are the means of triplicate samples, and the errors were calculated as the standard errors of the means.

\section{Additional files}

Additional file 1: Figure S1. The oxidation of D-glucose units of cellulose by laccase-TEMPO treatment.

Additional file 2: Figure S2. Standards for HPAEC-PAD analysis. (a) Glucuronic acid eluted with gradient 1, (b) gluconic acid eluted with gradient 1, (c) glucuronic acid eluted with gradient 2, and (d) gluconic acid eluted with gradient 2 .

Additional file 3: Figure S3. Oxygen consumption of Trametes hirsuta laccase $\left(10 \mathrm{nkat} \mathrm{ml}^{-1}\right.$ ) and $0.5 \mathrm{mM}$ mediator: HBT (blue line), ABTS (red line), TEMPO (green line), and AS (purple line). Measured for (a) 20 min and (b) $12 \mathrm{~h}$.

\section{Abbreviations}

ABTS: 2,2,'-azino-bis(3-ethylbenzothiazoline-6-sulfonic acid); AS: Acetosyringone; DM: Dry matter; ET: Electron transfer; G: Guaiacyl; HAT: Hydrogen atom transfer; HBT: 1-hydroxybenzotriazole; HPAEC-PAD: High-performance anion exchange chromatography with pulsed amperometric detection; LMT: Laccase-mediator treatment; NHA: N-hydroxy-N-phenylacetamide; PASC: Phosphoric acid swollen cellulose; S: Syringyl; SPS: Steam pre-treated spruce; TEMPO: 2,2,6,6-

tetramethylpiperidine-1-oxyl.

\section{Competing interests}

The authors declare that they have no competing interests.

\section{Authors' contributions}

UM conceived the study, carried out most of the experiments, analyzed the data, and drafted the manuscript. MK performed the PASC oxidation experiments and the oxygen consumption measurements and participated in the drafting of the manuscript. AV helped with the adsorption experiments and with interpreting the PASC oxidation analysis results, as well as drafting the manuscript. MA supervised, together with UM, MK's work and critically revised the manuscript. LV conceived the study, participated in its design, and critically revised the manuscript. All authors read and approved the final manuscript.

\section{Acknowledgements}

This study was funded by the Fortum Foundation and the EU Commission (Project: 222699, NEMO). The authors thank Laura Huikko and Taru Rautavesi for their assistance with the HPAEC-PAD analysis.

\section{Author details}

${ }^{1}$ Department of Food and Environmental Sciences, University of Helsinki, PO Box 27, Helsinki 00014, Finland. ${ }^{2} V T T$ Technical Research Centre of Finland, PO Box 1000, Espoo 02044, Finland. ${ }^{3}$ Department of Chemistry, Biotechnology and Food Science, Norwegian University of Life Sciences, PO Box 5003, Aas N-1432, Norway. 
Received: 6 October 2014 Accepted: 3 December 2014

Published online: 24 December 2014

\section{References}

1. Somerville C, Bauer S, Brininstool G, Facette M, Hamann T, Milne J, Osborne E, Paredez A, Persson S, Raab T, Vorwerk S, Youngs H: Toward a systems approach to understanding plant cell walls. Science 2004, 306:2206-2211.

2. Himmel ME, Ding SY, Johnson DK, Adney WS, Nimlos MR, Brady JW, Foust TD: Biomass recalcitrance: engineering plants and enzymes for biofuels production. Science 2007, 315:804-807.

3. Ramos LP: The chemistry involved in the steam treatment of lignocellulosic materials. Quim Nova 2003, 26:863-871.

4. Berlin A, Balakshin M, Gilkes N, Kadla J, Maximenko V, Kubo S, Saddler J: Inhibition of cellulase, xylanase and $\beta$-glucosidase activities by softwood lignin preparations. J Biotechnol 2006, 125:198-209.

5. Chernoglazov VM, Ermolova OV, Klyosov AA: Adsorption of high-purity endo-1,4- $\beta$-glucanases from Trichoderma reesei on components of lignocellulosic materials: cellulose, lignin, and xylan. Enzyme Microb Technol 1988, 10:503-507.

6. Converse AO, Ooshima H, Burns DS: Kinetics of enzymatic hydrolysis of lignocellulosic materials based on surface area of cellulose accessible to enzyme and enzyme adsorption on lignin and cellulose. Appl Biochem Biotechnol 1990, 24-25:67-73.

7. Ooshima H, Burns DS, Converse AO: Adsorption of cellulase from Trichoderma reesei on cellulose and lignacious residue in wood pretreated by dilute sulfuric acid with explosive decompression. Biotechnol Bioeng 1990, 36:446-452.

8. Palonen H, Tjerneld F, Zacchi G, Tenkanen M: Adsorption of Trichoderma reesei $\mathrm{CBH}$ I and EG II and their catalytic domains on steam pretreated softwood and isolated lignin. J Biotechnol 2004, 107:65-72.

9. Rahikainen J, Mikander S, Marjamaa K, Tamminen T, Lappas A, Viikari L, Kruus $\mathrm{K}$ : Inhibition of enzymatic hydrolysis by residual lignins from softwood - study of enzyme binding and inactivation on lignin-rich surface. Biotechnol Bioeng 2011, 108:2823-2834.

10. Nakagame S, Chandra RP, Saddler JN: The effect of isolated lignins, obtained from a range of pretreated lignocellulosic substrates, on enzymatic hydrolysis. Biotechnol Bioeng 2010, 105:871-879.

11. Solomon El, Sundaram UM, Machonkin TE: Multicopper oxidases and oxygenases. Chem Rev 1996, 96:2563-2605.

12. Thurston CF: The structure and function of fungal laccases. Microbiology 1994, 140:19-26.

13. Tadesse MA, D'Annibale A, Galli C, Gentili P, Sergi F: An assessment of the relative contributions of redox and steric issues to laccase specificity towards putative substrates. Org Biomol Chem 2008, 6:868-878.

14. Bourbonnais R, Paice MG: Oxidation of non-phenolic substrates: an expanded role for laccase in lignin biodegradation. FEBS Lett 1990, 267:99-102

15. Acunzo F, Galli C, Masci B: Oxidation of phenols by laccase and laccasemediator systems. Eur J Biochem 2002, 269:5330-5335.

16. Bourbonnais R, Leech D, Paice MG: Electrochemical analysis of the interactions of laccase mediators with lignin model compounds. Biochim Biophys Acta 1998, 1379:381-390.

17. Fabbrini M, Galli C, Gentili P: Comparing the catalytic efficiency of some mediators of laccase. J Molec Catal B Enzym 2002, 16:231-240.

18. Li K, Helm RF, Eriksson KEL: Mechanistic studies of the oxidation of a nonphenolic lignin model compound by the laccase/1-hydroxybenzotriazole redox system. Biotechnol Appl Biochem 1998, 27:239-243.

19. Cecchetto A, Fontana F, Minisci F, Recupero F: Efficient Mn-Cu and Mn-CoTEMPO-catalysed oxidation of alcohols into aldehydes and ketones by oxygen under mild conditions. Tetrahedron Lett 2001, 42:6651-6653.

20. De Mico A, Margarita R, Parlanti L, Vescovi A, Piancatelli G: A versatile and highly selective hypervalent iodine (III)/2,2,6,6-tetramethyl-1piperidinyloxyl-mediated oxidation of alcohols to carbonyl compounds. J Org Chem 1997, 62:6974-6977.

21. Galli C, Gentili P: Chemical messengers: mediated oxidations with the enzyme laccase. J Phys Org Chem 2004, 17:973-977.

22. Widsten $P$, Kandelbauer A: Laccase applications in the forest products industry: a review. Enzyme Microb Technol 2008, 42:293-307.

23. Kudanga T, Nyanhongo GS, Guebitz GM, Burton S: Potential applications of laccase-mediated coupling and grafting reactions: a review. Enzyme Microb Technol 2011, 48:195-208.
24. Mogharabi M, Faramarzi MA: Laccase and laccase-mediated systems in the synthesis of organic compounds. Adv Synth Catal 2014, 356:897-927.

25. Husain Q: Potential applications of the oxidoreductive enzymes in the decolorization and detoxification of textile and other synthetic dyes from polluted water: a review. Crit Rev Biotechnol 2006, 26:201-221.

26. Cañas Al, Camarero S: Laccases and their natural mediators: biotechnological tools for sustainable eco-friendly processes. Biotechnol Adv 2010, 28:694-705.

27. Camarero S, Ibarra D, Martínez MJ, Martínez ÁT: Lignin-derived compounds as efficient laccase mediators for decolorization of different types of recalcitrant dyes. App/ Environ Microbiol 2005, 71:1775-1784.

28. Johannes C, Majcherczyk A: Natural mediators in the oxidation of polycyclic aromatic hydrocarbons by laccase mediator systems. Appl Environ Microbiol 2000, 66:524-528.

29. Moilanen U, Kellock M, Galkin S, Viikari L: The laccase-catalyzed modification of lignin for enzymatic hydrolysis. Enzyme Microb Technol 2011, 49:492-498.

30. Palonen $H$, Viikari L: Role of oxidative enzymatic treatments on enzymatic hydrolysis of softwood. Biotechnol Bioeng 2004, 86:550-557.

31. Gutiérrez A, Rencoret J, Cadena EM, Rico A, Barth D, del Río JC, Martínez ÁT: Demonstration of laccase-based removal of lignin from wood and non-wood plant feedstocks. Bioresour Technol 2012, 119:114-122.

32. Rico A, Rencoret J, del Río JC, Martínez AT, Gutiérrez A: Pretreatment with laccase and a phenolic mediator degrades lignin and enhances saccharification of Eucalyptus feedstock. Biotechnol Biofuels 2014, 7:6.

33. Heap L, Green A, Brown D, van Dongen B, Turner N: Role of laccase as an enzymatic pretreatment method to improve lignocellulosic saccharification. Catal Sci Technol 2014, 4:2251-2259.

34. Bragd P, Van Bekkum H, Besemer A: TEMPO-mediated oxidation of polysaccharides: survey of methods and applications. Top Catal 2004, 27:49-66.

35. Saito T, Isogai A: TEMPO-mediated oxidation of native cellulose. the effect of oxidation conditions on chemical and crystal structures of the water-insoluble fractions. Biomacromolecules 2004, 5:1983-1989.

36. Patel I, Ludwig R, Haltrich D, Rosenau T, Potthast A: Studies of the chemoenzymatic modification of cellulosic pulps by the laccase-TEMPO system. Holzforschung 2011, 65:475-481.

37. Horn SJ, Vaaje-Kolstad G, Westereng B, Eijsink VG: Novel enzymes for the degradation of cellulose. Biotechnol Biofuels 2012, 5:1-13.

38. Rahikainen $J$, Evans JD, Mikander S, Kalliola A, Puranen T, Tamminen T, Marjamaa K, Kruus K: Cellulase-lignin interactions - the role of carbohydrate-binding module and $\mathrm{pH}$ in non-productive binding. Enzyme Microb Technol 2013, 53:315-321.

39. Bourbonnais R, Paice MG, Freiermuth B, Bodie E, Borneman S: Reactivities of various mediators and laccases with kraft pulp and lignin model compounds. Appl Environ Microbiol 1997, 63:4627-4632.

40. Mattinen M, Maijala P, Nousiainen P, Smeds A, Kontro J, Sipilä J, Tamminen T, Willför S, Viikari L: Oxidation of lignans and lignin model compounds by laccase in aqueous solvent systems. J Molec Catal B 2011, 72:122-129.

41. Studer MH, DeMartini JD, Davis MF, Sykes RW, Davison B, Keller M, Tuskan GA, Wyman CE: Lignin content in natural Populus variants affects sugar release. Proc Natl Acad Sci U S A 2011, 108:6300-6305.

42. Tamminen TL, Hortling BR: Isolation and characterization of residual lignin. In Advances in Lignocellulosics Characterization. Edited by Argyropoulos DS. Atlanta: Tappi Press; 1999:1-41.

43. Wood TM: Preparation of crystalline, amorphous, and dyed cellulase substrates. Meth Enzymol 1988, 160:19-25.

44. Rittstieg K, Suurnäkki A, Suortti T, Kruus K, Guebitz G, Buchert J: Investigations on the laccase-catalyzed polymerization of lignin model compounds using size-exclusion HPLC. Enzyme Microb Technol 2002, 31:403-410.

45. Suurnäkki A, Tenkanen M, Siika-aho M, Niku-Paavola ML, Viikari L, Buchert J: Trichoderma reesei cellulases and their core domains in the hydrolysis and modification of chemical pulp. Cellulose 2000, 7:189-209.

46. Sipos B, Benkő Z, Dienes D, Réczey K, Viikari L, Siika-aho M: Characterisation of specific activities and hydrolytic properties of cell-wall-degrading enzymes produced by Trichoderma reesei Rut C30 on different carbon sources. Appl Biochem Biotechnol 2010, 161:347-364.

47. Niku-Paavola ML, Karhunen E, Salola P, Raunio V: Ligninolytic enzymes of the white-rot fungus Phlebia radiata. Biochem J 1988, 254:877-883.

48. Lowry OH, Rosebrough NJ, Farr AL, Randall RJ: Protein measurement with the Folin phenol reagent. J Biol Chem 1951, 193:265-275. 
49. Várnai A, Viikari L, Marjamaa K, Siika-aho M: Adsorption of monocomponent enzymes in enzyme mixture analyzed quantitatively during hydrolysis of lignocellulose substrates. Bioresour Techno/ 2011, 102:1220-1227.

50. Rantanen H, Virkki L, Tuomainen P, Kabel M, Schols H, Tenkanen M: Preparation of arabinoxylobiose from rye xylan using family 10 Aspergillus aculeatus endo-1,4- $\beta$-D-xylanase. Carbohydr Polym 2007 68:350-359.

51. Sluiter A, Hames B, Ruiz R, Scarlata C, Sluiter J, Templeton D, Crocker D: Determination of Structural Carbohydrates and Lignin in Biomass. NREL Laboratory Analytical Procedure. [http://www.nrel.gov/biomass/pdfs/42618.pdf]

52. Ahlgren PA, Goring DAl: Removal of wood components during chlorite delignification of black spruce. Can J Chem 1971, 49:1272-1275.

53. Campbell WG, McDonald IRC: Chemistry of the wood cell wall. II. the isolation of beech and spruce acid-soluble and modified lignins. J Chem Soc 1952:3180-3183.

\section{Submit your next manuscript to BioMed Central and take full advantage of:}

- Convenient online submission

- Thorough peer review

- No space constraints or color figure charges

- Immediate publication on acceptance

- Inclusion in PubMed, CAS, Scopus and Google Scholar

- Research which is freely available for redistribution 